\title{
Simulation-Based Analysis of Ship Motions in Short-Crested Irregular Seas
}

\author{
Kıvanç Ali ANIL ${ }^{1}$, Devrim Bülent DANIŞMAN ${ }^{1}$, Kadir SARIÖZ1 \\ ${ }^{1}$ İstanbul Teknik Üniversitesi, Gemi İnşaatı ve Deniz Bilimleri Fakültesi, anil@itu.edu.tr; bulent. \\ danisman@itu.edu.tr; sarioz@itu.edu.tr
}

\begin{abstract}
Demonstration of the seakeeping calculation results other than polar diagrams and Cartesian plots is important during the initial and detail design stages of naval platforms due to the necessity of numerical simulations (time series data) for the design and validation of the systems on board. These time series simulations are called as "real time computer experiments". Similar simulation algorithms for ship motions and wave elevation are also used by ship-handling simulators for realistic visualization. The goal of this paper is to create a basis for the simulation-based analysis of ship motions and wave elevation for future design and validation studies for both the naval platform itself and the systems on board. The focus of this paper is the clarification of the theoretical background of this process, i.e. all formulations required to create and validate a ship motion and wave surface simulation are given in detail. The results of this study may also be used in ship-handling simulators or helicopter landing on ship simulations.
\end{abstract}

Keywords: Seakeeping Simulation, Ship Motions, Short-Crested Irregular Seas.

\section{Kısa Dalga Tepeli Karışık Denizlerdeki Gemi Hareketlerinin Simülasyona Dayalı Analizi}

$\ddot{O} z$

Denizcilik hesap sonuçlarının polar diyagramlar ve Kartezyen grafikler dışında gösterimi, deniz platformlarının başlangıç ve detay tasarım aşamalarında gemideki sistemlerin tasarımı ve doğrulaması için sayısal simülasyonların (zaman serisi veri) gerekliliği nedeniyle önem arz etmektedir. Bahse konu zaman serisi simülasyonları "gerçek zamanlı bilgisayar deneyleri" olarak adlandırılmaktadır. Gemi hareketleri ve dalga yüksekliği için benzer simülasyon algoritmaları, gemi kullanma simülatörleri tarafindan gerçekçi görselleştirme için de kullanılmaktadır. Bu makalenin amacl, deniz platformunun kendisi ve üzerindeki sistemler için gelecekteki tasarım ve doğrulama çalışmalarında kullanılmak üzere, gemi hareketlerinin ve dalga yüksekliğinin simülasyona dayalı analizi için bir temel oluşturmaktır. Makalenin odak noktası bu sürecin teorik altyapısının açıklığa kavușturulması olup, bir gemi hareketini ve dalga yüzey simülasyonunu oluşturmak ve doğrulamak için gerekli tüm formülasyonlar ayrıntılı olarak verilmektedir. Çalışmanın sonuçları gemi kullanma simülatörlerinde veya gemiye konuşlu helikopter simülasyonlarında da kullanılabilir.

Anahtar Kelimeler: Denizcilik Simülasyonu, Gemi Hareketleri, Kısa Dalga Tepeli Karışık Deniz. 


\section{Introduction}

Demonstration of the seakeeping calculation results is important during the initial and detail design stages of naval platforms. In order to confirm the fulfillment of the mission criteria sets for the platform, polar diagrams and Cartesian plots of root mean square (rms) or significant values of responses are commonly used, but numerical simulations (time series data, time history) are also needed for the design and validation of the systems on board. These systems mainly include active roll stabilizer fins, active motion interceptors, rudder roll stabilization, helicopter securing \& traversing, helicopter visual landing aid, and all sensors \& weapons. The simulated time series of ship motions and wave elevation may also be used for the naval platform itself to derive the shear force and bending moment distribution of ship sections using ship hydroelasticity theory, as investigated by Belik [1]. These time series simulations are called as "real time computer experiments" [2, 3]. Similar simulation algorithms for ship motions and wave elevation are also used by ship-handling simulators for realistic visualization, as presented by Yeo et al. [4]. The results of this study may also be used in mooring simulations [5] or helicopter landing on ship simulations [6].

\section{Methodology}

An in-house ship motion and wave surface simulation (in short-crested irregular seas) code is developed in a $\mathrm{C}++$ programming language which can be controlled by the user in real time on screen. The visualization is achieved using Object-Oriented Graphics Rendering Engine (OGRE) Software Development Kit [7], as shown in Figure 1. The simulation uses the basic methodology of the real time uncontrollable ship motion simulation (in long-crested irregular seas) which was written in Virtual Reality Modelling
Language (VRML) by Adanır et al. [8].

The current simulation works real time and has no time limitation (infinite simulation duration). Time step of the "real time simulation" is the time passed since the last frame rendered, i.e. depends on the frame rate. The simulation can be accelerated or decelerated using predefined large or small fixed time steps for analysis purpose. The simulation has also real time controllable parameters for the ship and the environment. The controllable ship parameters are the speed and rudder angle. The controllable environment parameters are the sea area, sea-state and wave direction. Sea areas are defined by appropriate sea-spectra. Sea-states are defined by the World Meteorological Organization (WMO) standard sea-state code (Douglas Scale).

Ship responses in short-crested irregular seas are calculated for the selected sea-state and sea-spectrum (sea area). There is also a long-crested irregular seas option for the analysis purpose. Generation of the time series data for the seakeeping simulation (ship responses) is performed by the similar superposition algorithm indicated by Perez [9], using pre-calculated frequency domain Response Amplitude Operators (RAOs) for the selected sea-state and sea-spectrum. The algorithm is based on the St. Denis and Pierson's [10] application of the principle of superposition to the ship motion problem.

The three Cartesian coordinate systems defined by Beck et al. [11] are used to determine the ship motions for the seakeeping simulation. These are the earthfixed $\left(x_{0}, y_{0}, z_{0}\right)$, moving(inertial) $(x, y, z$ ), and the body-fixed ( $\bar{x}, \bar{y}, \bar{z})$ system. The $x_{0}-y_{0}$ plane of the earth-fixed system and the $x-y$ plane of inertial system coincide with the calm water level. For the bodyfixed coordinate system which moves with all the motions of the ship, the $\bar{x}-\bar{y}$ plane coincides with the ship's calm water-plane, with $\bar{z}$ axis normal to it upwards, i.e. the 


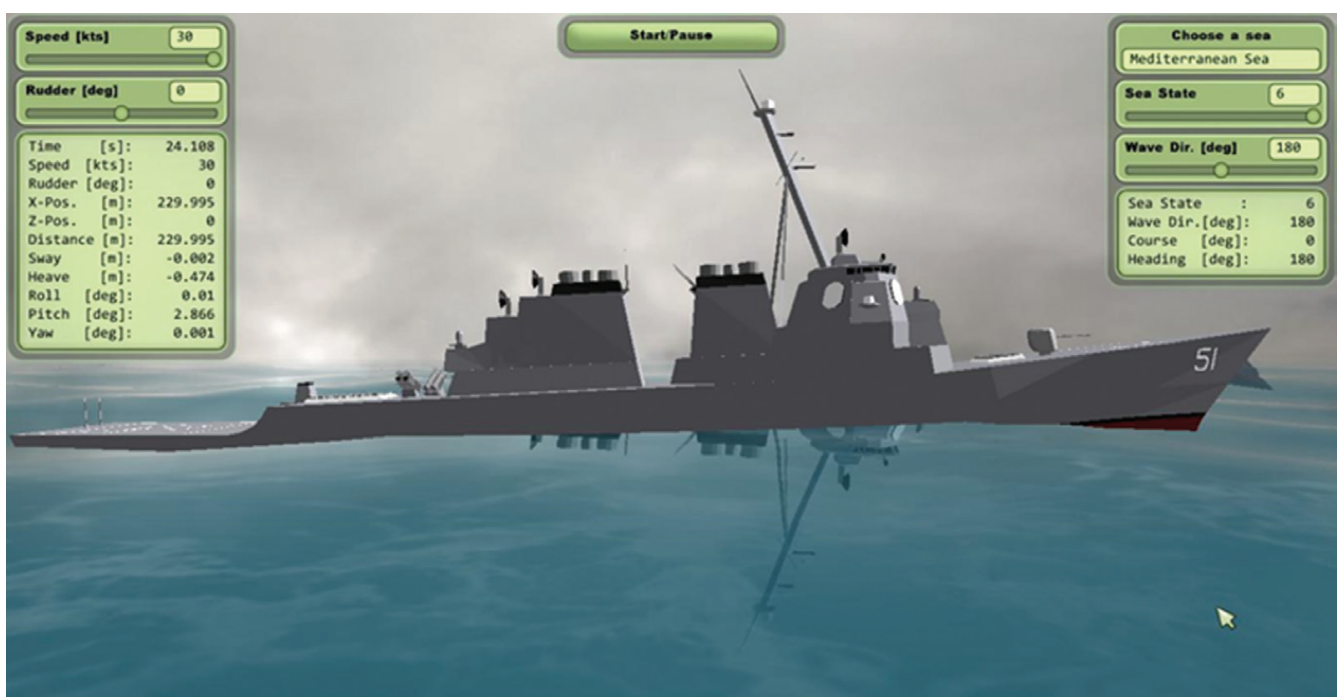

Figure 1. Ship Motion and Wave Surface Simulation

origin is in the calm water-plane at any convenient point between fore and aft in the center plane, such as amidships. In this study the $\bar{z}$ axis is through the center of gravity of the ship, as Salvesen, Tuck and Faltinsen [12] specified. The orientation of the body-fixed system relative to the inertial system gives the translational and rotational motions of the ship. The inertial to earth-fixed system transformation is given by:

$$
\begin{aligned}
& x_{0}=x+V_{S} t \\
& y_{0}=y \\
& z_{0}=z
\end{aligned}
$$

where $V_{s}$, and represents the ship speed and time respectively. There are several cameras (views) in the simulation located on all coordinate systems, which makes analysis of ship motions possible from different angles. The bridge view of the body-fixed system can be used for a ship-handling simulator.

The time series data for the short-crested irregular sea surface is generated by the well-known superposition algorithm that follows St. Denis and Pierson [10], for the selected sea-state and sea-spectrum. There is also a long-crested option for analysis purpose. The wave surface is defined in the earth-fixed coordinate system. The wave visualization is performed using the addon library of OGRE Software Development Kit named "Hydrax Version 0.5.1" [13]. In order to create an infinite wave surface, "Projected Grid" option of Hydrax based on Johanson [14] thesis is used. New Hydrax subroutines are written for the desired seaspectra.

As a beginning of a future maneuvering simulation study, smooth turning of the ship is achieved by using the interpolated values of tactical diameter with respect to the rudder angle and ship speed. The heading angle and the orientation of the earthfixed and inertial coordinate system are updated when the rudder angle is changed. Coordinate system transformation for the maneuvering simulation is not in the scope of this study.

The current simulation does not fit simulation interoperability standards like High Level Architecture (HLA).

\section{Theoretical Background}

The focus of this paper is the explaining of the theoretical background of a ship motion and wave surface simulation. 
Although the readers are aware of most the formulations given in this paper, all formulations including Sea-State, SeaSpectra, Directional Spectrum, Derived Responses which are required to create such a simulation are given in the following subsections.

\subsection{Sea-State}

Sea-states are defined by the WMO standard sea-state code (Douglas Scale) i.e. in the WMO Code Table 3700 [15]. This code table is used for recording the sea-state by an observer. The wave height values recorded by the observer refer to the well-formed wind waves of the open sea [15]. On the other hand, the definition of the "significant wave height" according to STANAG 4154 [16] is as follows: "If all the wave heights (peak to trough) of a wave record are measured, the significant wave height is the mean value of the highest one-third of all the wave heights. It is approximately equal to the wave height estimated by an observer". The statistical term "significant waves" is first introduced by Sverdrup and Munk [17] as "the mean height of the highest one-third of all the waves" (cited by Longuet-Higgins [18]). Sverdrup and Munk [17] implied that "a careful observer who attempts to establish the character of the higher waves will tend to record the significant waves". Therefore the wave height range of this sea-state code (WMO Code Table 3700) can be regarded as significant wave height range for the naval engineering purpose, as shown in Table 1.

\subsection{Sea-Spectra}

The random nature of an irregular sea can be described mathematically by the seaspectrum formulas. $12^{\text {th }}$ International Towing Tank Conference (ITTC) [19] recommended the following spectral formulation for open ocean wave conditions;

$$
S(\omega)=\frac{A}{\omega^{5}} \exp \left(-\frac{B}{\omega^{4}}\right)
$$

Table 1. Sea-States, after [15] \& [27]

\begin{tabular}{|c|c|c|}
\hline $\begin{array}{c}\text { Sea- } \\
\text { State }\end{array}$ & $\begin{array}{c}\text { Significant } \\
\text { Wave Height } \\
\text { Range } \\
\text { (in meters) }\end{array}$ & $\begin{array}{c}\text { Mean Values of } \\
\text { Significant Wave } \\
\text { Height Range } \\
\text { (in meters) }\end{array}$ \\
\hline $0-1$ & $0,00-0,10$ & 0,05 \\
\hline 2 & $0,10-0,50$ & 0,30 \\
\hline 3 & $0,50-1,25$ & 0,88 \\
\hline 4 & $1,25-2,50$ & 1,88 \\
\hline 5 & $2,50-4,00$ & 3,25 \\
\hline 6 & $4,00-6,00$ & 5,00 \\
\hline 7 & $6,00-9,00$ & 7,50 \\
\hline 8 & $9,00-14,00$ & 11,50 \\
\hline 9 & $\geq 14,00$ & $\geq 14,00$ \\
\hline
\end{tabular}

where $\omega$ is the circular wave frequency in radians per second, $A$ and $B$ are constants. If no information except the significant wave height $H_{1 / 3}$ is available about the sea area then,

$$
A=0.0081 g^{2}, \quad B=\frac{3.11}{H_{1 / 3}^{2}}
$$

Here, $g$ is the acceleration of gravity. If average period $T_{1}$ is also known then,

$$
A=173 \frac{H_{1 / 3}^{2}}{T_{1}^{4}}, \quad B=\frac{691}{T_{1}^{4}}
$$

Equation (2) along with Equation (3) is a form of the "Pierson-Moskowitz Spectrum" which was first introduced by Pierson and Moskowitz [20] in 1964 and called as "ITTC One Parameter Spectrum". Equation (2) along with Equation (4) is a form of the "Bretschneider Spectrum" which was first introduced by Bretschneider [21] in 1959 and called as "ITTC Two-Parameter Spectrum". This spectrum is also called as "The Modified Pierson-Moskowitz Spectrum", but the reason is not clear since the Bretschneider Spectrum is devised before the Pierson-Moskowitz Spectrum [22].

$15^{\text {th }}$ ITTC [23] made an amendment to the above spectral formulation and 
recommended the use of only Equation (2) along with Equation (4) as a standard spectral formulation for open ocean wave conditions. $15^{\text {th }}$ ITTC recommended the following spectral formulation which is a form of the "Joint North Sea Wave Project (JONSWAP) Spectrum [24]" for fetchlimited situations;

$S_{J}(\omega)=0.658 S(\omega) 3.3^{\exp -\left(\frac{0.206 \omega T_{1}-1}{\sqrt{2} \sigma}\right)^{2}}$

where,

$$
\begin{aligned}
& \sigma=0.07 \text { for } \omega \leq \frac{4.85}{T_{1}} \\
& \sigma=0.09 \text { for } \omega>\frac{4.85}{T_{1}}
\end{aligned}
$$

Here $S(\omega)$ is the "ITTC Two-Parameter Spectrum" which was defined by Equation (2) along with Equation (4). 17 ${ }^{\text {th }}$ ITTC [25] made a replacement for the above fetchlimited spectral formulation as a draft recommendation, but it was not adopted as a final recommendation by the $17^{\text {th }}$ ITTC seakeeping committee.

The significant wave height $H_{1 / 3}$ and average period $T_{1}$ are the main input of the above recommended spectra. On the other hand, STANAG 4154 [16] recommended to use the significant wave height and the modal wave period $T_{m}$ to characterize the nature of the seaway. The modal wave period corresponds to the maximum wave energy, i.e. the peak frequency (modal wave frequency) of the spectrum curve $[16,26]$. The relation between the average and the modal wave period is as follows [26];

$T_{m}=1.296 T_{1}$

The constants (4) become as follows, using Equation (7);

$$
A=488 \frac{H_{1 / 3}^{2}}{T_{m}^{4}}, \quad B=\frac{1949}{T_{m}^{4}}
$$

The JONSWAP Spectrum in terms of modal wave period is as follows [26];

$$
S_{J}(\omega)=0.658 S(\omega) 3.3 \exp \left(-\frac{1}{2 \sigma^{2}}\left(\frac{\omega T_{m}}{2 \pi}-1\right)^{2}\right)
$$

where,

$$
\begin{aligned}
& \sigma=0.07 \text { for } \omega \leq \frac{2 \pi}{T_{m}} \\
& \sigma=0.09 \text { for } \omega>\frac{2 \pi}{T_{m}}
\end{aligned}
$$

The mean values of the significant wave height range can be used to define the sea-state as shown in Table 1, but the corresponding modal wave periods for each sea-state should be known to define the sea area. $18^{\text {th }}$ ITTC [27] gives the range and most probable modal wave periods of North Atlantic, North Pacific, and Northern Hemisphere for each sea-state.

ITTC One-, ITTC Two-Parameter and JONSWAP sea-spectra at "sea-state 6" for the Northern Hemisphere are shown in Figure 2. The dimension of the sea-spectra is "squared length multiplied by time", since the spectral ordinates are the measure of the average squared value of the wave amplitude of the corresponding frequency abscissa [10]. The area under the spectrum curve is equal to the "variance" of the large irregular wave time history which has a zero mean [26];

$m_{0}=\int_{0}^{\infty} S(\omega) d \omega$

This is why the sea-spectrum is also named as "variance spectrum" by Beck et al. [11]. Since the irregular wave time history has been agreed to hold a zero mean, variance is equal to the "mean square value" [28].

The "standard deviation" or "rms value" is equal to the square root of variance [28]. The significant wave amplitude $\zeta_{1 / 3}$ is 
equal to the double rms amplitude. Hence the following equation is valid for the significant wave height [26];

$$
H_{1 / 3}=2 \zeta_{1 / 3}=2 \times 2 \sqrt{m_{0}}=4 \sqrt{m_{0}}
$$

The peak frequency of the spectrum curve equal to the modal wave frequency $\omega_{m}$, as mentioned before and therefore the modal wave period is as follows;

$T_{m}=\frac{2 \pi}{\omega_{m}}$

It is obvious that one can derive the same values of the significant wave height and modal wave period from a seaspectrum curve, which has been calculated using above spectral formulas in terms of the significant wave height and modal wave period.

\subsection{Directional Spectrum}

The sea-spectra described above is unidirectional, i.e. can be used for a description of a long-crested irregular sea. In order to describe a short-crested irregular sea it is required to have a multidirectional spectrum. Multi-directional or shortly "directional" spectrum can be defined as follows [9];

$S(\omega, v)=M(v-\mu) S(\omega)$

where $M(v-\mu)$ is the spreading function and $S(\omega)$ is the unidirectional spectrum. Here $\mu$ is the primary (dominant) and $v$ is the secondary wave direction relative to the earth-fixed coordinate system. The range of the secondary wave directions is defined as follows [26];

$-v_{\max } \leq v-\mu \leq v_{\max }$

where $v_{\max }$ is the wave spreading angle. The spreading function distributes the total energy of the unidirectional spectrum over the range of secondary wave directions from $-v_{\max }$ to $v_{\max }$ [26]. Therefore, the variance of the irregular wave time history (11) becomes as follows [10] (cited by Perez [9]);

$m_{0}=\int_{0}^{\infty} S(\omega) d \omega=\int_{0}^{\infty} \int_{-v_{\max }+\mu}^{v_{\max }+\mu} S(\omega, v) d v d \omega$

This equation means that volume under the directional spectrum surface is equal to the variance of the irregular wave time history with has a zero mean. The volume under the directional spectrum surface is also equal to the area under the

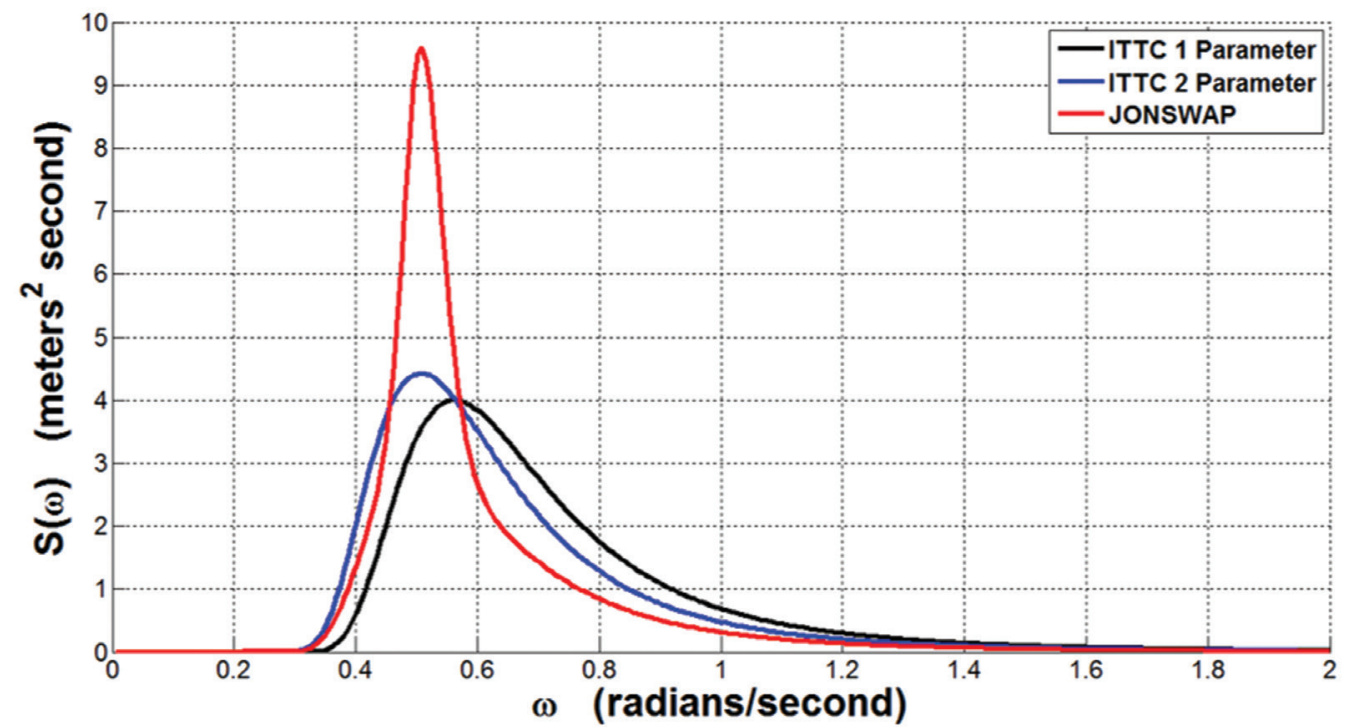

Figure 2. Sea-Spectra at "Sea-State 6" for the Northern Hemisphere 
corresponding spectrum curve. Following equation can be written from Equation (16);

$$
S(\omega)=\int_{-v_{\max }+\mu}^{v_{\max }+\mu} S(\omega, v) d v=\int_{-v_{\max }+\mu}^{v_{\max }+\mu} M(v-\mu) S(\omega) d v
$$

The above equation can be rewritten as;

$$
S(\omega)=\int_{-v_{\max }}^{v_{\max }} M(v-\mu) S(\omega) d(v-\mu)
$$

The spreading function is defined as follows [26];

$$
M(v-\mu)=D \cos ^{m}\left(\frac{\pi}{2 v_{\max }}(v-\mu)\right)
$$

where $D$ is a constant and $m$ is the spreading index (a positive integer). If we set;

$$
v^{\prime}=\frac{\pi}{2 v_{\max }}(v-\mu) \Rightarrow d v^{\prime}=\frac{\pi}{2 v_{\max }} d(v-\mu)
$$

Equation (18) becomes [26];

$$
S(\omega)=\frac{2 v_{\max }}{\pi} \int_{\frac{\pi}{2 v_{\max }}\left(-v_{\max }\right)}^{\frac{\pi}{2 v_{\max }} v_{\max }} D \cos ^{m}\left(v^{\prime}\right) S(\omega) d v^{\prime}
$$

The constant $D$ can be written from the above equation as follows [26];

$$
D=\frac{\pi}{2 v_{\max }} \frac{1}{\int_{-\pi / 2}^{\pi / 2} \cos ^{m}\left(v^{\prime}\right) d v^{\prime}}=\frac{\pi}{4 v_{\max }} \frac{1}{\int_{0}^{\pi / 2} \cos ^{m}\left(v^{\prime}\right) d v^{\prime}}
$$

Integration of the above equation for different values of $m$ yields;

$$
D=\left\{\begin{array}{cl}
\frac{1}{2 v_{\max }} & \text { for } m=0 \\
\frac{\pi}{4 v_{\max }} & \text { for } m=1 \\
\frac{1 \cdot 3 \cdot 5 \cdots m}{2 \cdot 4 \cdot 6 \cdots(m-1)} \frac{\pi}{4 v_{\max }} & \text { for } m \text { odd }>1 \\
\frac{2 \cdot 4 \cdot 6 \cdots m}{1 \cdot 3 \cdot 5 \cdots(m-1)} \frac{1}{2 v_{\max }} & \text { for } m \text { even }>0
\end{array}\right.
$$

Following equation is also valid for even values of $m$ other than zero, where $n=m / 2$ [9];

$M(v-\mu)=\frac{2^{(2 n-1)} n !(n-1) !}{\pi(2 n-1) !} \cos ^{2 n}(v-\mu)$ for $-\frac{\pi}{2} \leq v-\mu \leq \frac{\pi}{2}$ (24)
In this study, spreading index $m$ is 2 , and the spreading angle $v_{\max }$ is $\pi / 2$, which is the most common practice to represent short-crested seas for ship design purposes. Therefore, Equation (14) becomes as follows [26];

$$
S(\omega, v)=\frac{2}{\pi} \cos ^{2}(v-\mu) S(\omega)
$$

The directional ITTC Two-Parameter seaspectrum derived from Equation (25) at "sea-state 6" for the Northern Hemisphere is shown in Figure 3.

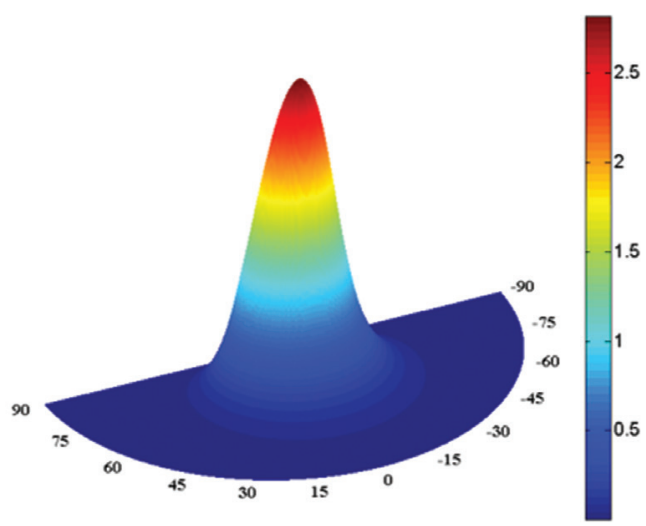

Figure 3. Directional ITTC Two-Parameter Spectrum at "sea-state 6" for the Northern Hemisphere

\subsection{Generation of the Time Series}

So far it has been shown that the seaspectrum formulas can be used to define the random characteristics of an irregular sea. A similar spectral formulation can be used to investigate ship responses to irregular waves since both are random processes. Under the assumption of linearity for the ship motions, St. Denis and Pierson [10] used the linear superposition theory and the spectral analysis techniques developed in other disciplines and introduced an innovative method which associates the spectral density of ship responses to the input sea-spectrum to determine the statistics of the ship motions in irregular seas. In this method, the principle of superposition allows the 
ship responses in irregular waves to be the sum of the responses to regular waves of all frequencies of the input sea-spectrum. Therefore, responses can be represented by the spectral density functions (motion or response spectra) similar to the sea-spectra and the area under these motion spectra gives the variance of the corresponding response amplitude [11, 12, 29]. Price and Bishop [28] described further developments and details about St. Denis and Pierson's [10] approach [11, 30].

Following these studies, generation of the time series of numerical simulations can be performed. Based on this method, from any irregular wave time history, resultant sea-spectrum can be derived. The inverse of this procedure is also available, i.e. superposition of a large number of sine or cosine wave components assumed to have a definite frequency and a random phaseshift angle produces an irregular wave time history [26, 11]. The same back and forth process is also valid in the ship responses.

The time series data for a long-crested irregular wave surface defined in the earthfixed coordinate system can be generated with the following algorithm as indicated by Perez [9];

$\zeta\left(x_{0}, y_{0}, t\right)=\sum_{n=1}^{N} \bar{\zeta}_{n} \cos \left(\omega_{n} t+\varepsilon_{n}-k_{n}\left(x_{0} \cos \mu-y_{0} \sin \mu\right)\right)$

Here $\bar{\zeta}_{n}, \varepsilon_{n}, k_{n}$ are the wave amplitude, random phase-shift angle, and the wave number of each component respectively, and $\mu$ is the wave direction relative to the earth-fixed coordinate system. Following equation is valid for the amplitudes of the wave components in the limit as $\delta \omega$ approaches zero [11];

$$
\frac{1}{2} \bar{\zeta}_{n}^{2}=S\left(\omega_{n}\right) \delta \omega
$$

Therefore, each component amplitude can be found as follows if $\delta \omega$ is small enough [11];

$\bar{\zeta}_{n}=\sqrt{2 S\left(\omega_{n}\right) \delta \omega}$

The time series data for a short-crested irregular wave surface can be generated with the following algorithm as indicated by Perez [9];

$\zeta\left(x_{0}, y_{0}, t\right)=\sum_{n=1}^{N} \sum_{m=1}^{M} \bar{\zeta}_{n, m} \cos \left(\omega_{n} t+\varepsilon_{n, m}-k_{n}\left(x_{0} \cos v_{m}-y_{0} \sin v_{m}\right)\right)$

Here $v_{m}$ is the each secondary wave direction relative to the earth-fixed coordinate system;

$\mu-v_{\max } \leq v_{m} \leq \mu+v_{\max }$

where, if $v_{m}<0$, then $v_{m}=v_{m}+2 \pi$.

For a directional spectrum (14), component amplitude can be found as follows [11];

$$
\bar{\zeta}_{n, m}=\sqrt{2 S\left(\omega_{n}, v_{m}\right) \delta \omega \delta v}
$$

Long- and short-crested irregular wave surfaces derived from above formulations at a time are shown in Figure 4.

The time series data for the ship responses is also calculated based on the St. Denis and Pierson [10]. The input wave spectrum and the RAOs for the ship are required for this purpose [29]. St. Denis and Pierson [10] defined the RAO as "the amplitude of the response to the wave amplitude of unity". In other words, RAO is the non-dimensional motion amplitude. Linear motion (surge, sway, heave) amplitudes are divided by the wave
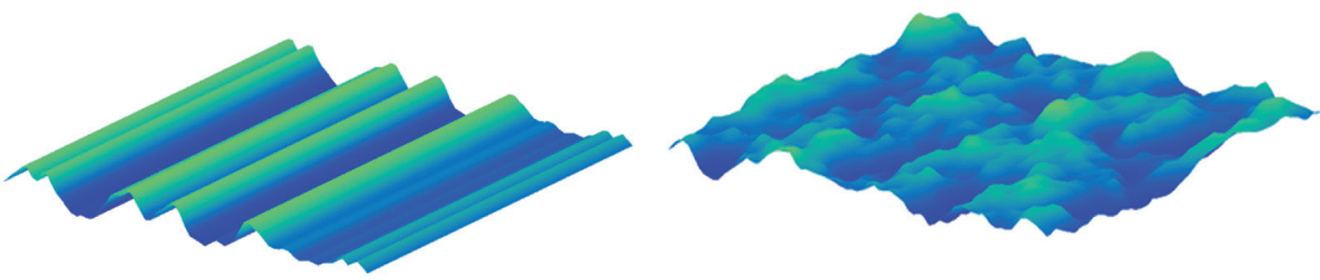

Figure 4. Long-Crested (Left), Short-Crested (Right) Irregular Wave Surface 
amplitude $\bar{\zeta}$, angular motion (roll, pitch, yaw) amplitudes are divided by the wave slope amplitude $k \bar{\zeta}$. The RAO is also named as "transfer function" in other disciplines. It is the ratio of wave amplitude or wave slope amplitude "transferred" to the response amplitude by the ship which is supposed to be a "system" [26]. Essentially, the modulus (absolute value) of the complex transfer function (non-dimensional complex motion amplitude) is defined as the RAO [11]. Consequently, the argument of the complex transfer function is the phase-shift angle of the response. However, sometimes the term RAO is used for the complex transfer function itself.

On a moving ship, the responses are experienced at the encounter frequency, not the wave frequency. In deep water following equation is valid for the encounter frequency [26];

$$
\omega_{e}=\omega-\frac{\omega^{2} V_{S}}{g} \cos \chi
$$

Here, $g$ is the acceleration of gravity, $V_{S}$ is the ship speed and $\chi$ is the "heading angle" or "encounter angle" which is the ship course relative to the primary wave direction;

$$
\chi=\text { course }-\mu
$$

where, if $\chi<0$, then $\chi=\chi+2 \pi$.

Since $9^{\text {th }}$ ITTC [31] it has been agreed that heading angle of $0^{\circ}$ represents following seas and $180^{\circ}$ represents the head seas. The sea-spectrum should be also transformed into the "encounter spectrum", which has the same area under the spectrum curve, to cover the range of encounter frequencies on board. The encounter spectrum can be calculated as follows [26];

$$
S\left(\omega_{e}\right)=S(\omega) \frac{g}{g-2 \omega V_{S} \cos \chi}
$$

The product of the encounter spectrum with the square of the RAO of the desired response gives the corresponding motion (response) spectrum [29];
$S_{\eta i}\left(\omega_{e}\right)=\left|H_{i}\left(\omega_{e}\right)\right|^{2} S\left(\omega_{e}\right)$ for $i=1,2, \ldots, 6$

Here $i$ is the motion index for surge, sway, heave, roll, pitch yaw respectively. Similar to the sea-spectra, the area under these motion spectra gives the corresponding motion amplitude variance [26];

$m_{i 0}=\int_{0}^{\infty} S_{\eta i}\left(\omega_{e}\right) d \omega_{e}$

Alternative formulation for the motion spectra in wave frequency domain is as follows [26];

$S_{\eta i}(\omega)=\left|H_{i}\left(\omega, V_{S}, \chi\right)\right|^{2} S(\omega)$ for $i=1,2, \ldots, 6$

Note that, the RAO in Equation (37) is equal to the RAO in Equation (35), which is just for the demonstration of the domain;

$H_{i}\left(\omega, V_{S}, \chi\right)=H_{i}\left(\omega_{e}\right)$

The ordinates of motion spectrum in the wave frequency domain (37) have no physical meaning, but the areas under both motion spectra, i.e. the motion amplitude variances are equal [26];

$m_{i 0}=\int_{0}^{\infty} S_{\eta i}(\omega) d \omega=\int_{0}^{\infty} S_{\eta i}\left(\omega_{e}\right) d \omega_{e}$

Similar to (27), the following equation can be written for the motion amplitude in the limit as $\delta \omega$ approaches zero;

$\frac{1}{2}\left|\bar{\eta}_{i, n}\right|^{2}=S_{\eta i}\left(\omega_{n}\right) \delta \omega$

Therefore, motion amplitudes for each component can be found as follows if $\delta \omega$ is small enough;

$\left|\bar{\eta}_{i, n}\right|=\sqrt{2 S_{\eta i}\left(\omega_{n}\right) \delta \omega}$

In short-crested seas, component amplitude can be found as follows, similar to Equation (31);

$\left|\bar{\eta}_{i, n, m}\right|=\sqrt{2 S_{\eta i}\left(\omega_{n}, v_{m}\right) \delta \omega \delta v}$

where;

$S_{\eta i}\left(\omega_{n}, v_{m}\right)=\left|H_{i}\left(\omega_{n}, V_{S}, \chi_{m}\right)\right|^{2} S\left(\omega_{n}, v_{m}\right)$ 
Here $\chi_{m}$ is the heading angle, i.e. the ship course relative to the each secondary wave direction $v_{m}$;

$\chi_{m}=$ course $-v_{m}$

where, if $\chi_{m}<0$, then $\chi_{m}=\chi_{m}+2 \pi$.

From (31) and (43), Equation (42) can be rewritten as follows;

$$
\left|\bar{\eta}_{i, n, m}\right|=\bar{\zeta}_{n, m}\left|H_{i}\left(\omega_{n}, V_{S}, \chi_{m}\right)\right|
$$

The time series data for the seakeeping simulation (ship responses) in shortcrested seas can be generated with the similar algorithm as indicated by Perez [9], using pre-calculated frequency domain RAOs for the selected sea-state and seaspectrum;

$$
\begin{aligned}
& \eta_{i}(t)=\sum_{n=1}^{N} \sum_{m=1}^{M}\left|\bar{\eta}_{i, n, m}\right| \cos \left(\omega_{e n, m} t+\sigma_{i, n, m}+\varepsilon_{n, m}\right) \text { for } \quad i=1,2,3 \\
& \eta_{i}(t)=\sum_{n=1}^{N} \sum_{m=1}^{M}\left|\bar{\eta}_{i, n, m}\right| k_{n} \cos \left(\omega_{e n, m} t+\sigma_{i, n, m}+\varepsilon_{n, m}\right) \text { for } \quad i=4,5,6
\end{aligned}
$$

Here $\sigma_{i, n, m}$ is the component phase-shift angle of the response. Encounter frequency for each heading angle (44) is as follows

$$
\omega_{e n, m}=\omega_{n}-\frac{\omega_{n}^{2} V_{S}}{g} \cos \chi_{m}
$$

The time series data for the seakeeping simulation (ship responses) in long-crested seas can be also generated by the above formula with $M=1$ and $d v=1$ [9].

\subsection{Derived Responses}

The time series of the derived responses like absolute or relative motions, accelerations; vertical distortion, shear force and bending moment distribution of ship sections can be obtained by the "real time computer experiments". The excessive motions, deck wetness, slamming or emergence at any location can be observed and analyzed from the relative motion time history.

As an example, the absolute vertical motion involves heave and pitch motions only for the ships in long-crested irregular head seas. The time series data for the absolute vertical motion at any point of the ship can be generated as follows;

$\eta_{A V}(t)=\eta_{3}(t)-\bar{x} \sin \left(\eta_{5}(t)\right)$

where $\bar{x}$ is the distance from the center of the body-fixed coordinate system. Note that sine of a small angle is equal to the angle itself in radians. Therefore, the above equation becomes as follows;

$\eta_{A V}(t)=\eta_{3}(t)-\bar{x} \eta_{5}(t)$

Likewise, the vertical component of the angular pitch motion RAO at any point of the ship becomes as follows;

$\left|H_{5 V}\left(\omega_{e}\right)\right|=\bar{x} k\left|H_{5}\left(\omega_{e}\right)\right|$

where $k$ is the wave number.

Superposition of the amplitudes of two simple harmonic motions, acting in the "same" direction is given by the following equation [33];

$$
A=\sqrt{A_{1}^{2}+A_{2}^{2}+2 A_{1} A_{2} \cos \left(\theta_{1}-\theta_{2}\right)}
$$

where $A_{1}, \theta_{1}$ and $A_{2}, \theta_{2}$ are the amplitudes and phases respectively. The resultant phase is given by the following equation [33];

$$
\theta=\arctan \left(\frac{A_{1} \sin \theta_{1}+A_{2} \sin \theta_{2}}{A_{1} \cos \theta_{1}+A_{2} \cos \theta_{2}}\right)
$$

Since RAO is the non-dimensional motion amplitude, the superposition of heave and vertical component of pitch RAOs acting in the "opposite" direction becomes as follows;

$\left|H_{A V}\left(\omega_{e}\right)\right|=\sqrt{\left|H_{3}\right|^{2}+\left|H_{5 V}\right|^{2}-2\left|H_{3}\right|\left|H_{5 V}\right| \cos \left(\sigma_{3}-\sigma_{5}\right)}$

The above equation is for the RAO of the absolute vertical motion at any point of the ship in long-crested irregular head seas. The resultant phase becomes;

$\sigma_{A V}=\arctan \left(\frac{\left|H_{3}\right| \sin \sigma_{3}-\left|H_{5 V}\right| \sin \sigma_{5}}{\left|H_{3}\right| \cos \sigma_{3}-\left|H_{5 V}\right| \cos \sigma_{5}}\right)$

The absolute longitudinal, lateral and vertical motion formulations for six degrees of freedom are given by Lloyd [26]. For example, the RAO and the phase of the absolute vertical motion which involves 
heave, pitch and roll motions are given by following equations;

$$
\begin{aligned}
& \left|H_{A V}\left(\omega_{e}\right)\right|=\sqrt{P_{11}^{2}+P_{12}^{2}} \\
& \sigma_{A V}=\arctan \left(\frac{P_{12}}{P_{11}}\right)
\end{aligned}
$$

where;

$$
\begin{aligned}
& P_{11}=\left|H_{3}\right| \cos \sigma_{3}+\left|H_{4 V}\right| \cos \sigma_{4}-\left|H_{5 V}\right| \cos \sigma_{5} \\
& P_{12}=\left|H_{3}\right| \sin \sigma_{3}+\left|H_{4 V}\right| \sin \sigma_{4}-\left|H_{5 V}\right| \sin \sigma_{5}
\end{aligned}
$$

If there is no roll motion, the above six degrees of freedom formulation yields to the Equation (53) and (54) using appropriate trigonometric identities. The corresponding absolute motion spectrum can be found similar to Equation (35);

$$
S_{A V}\left(\omega_{e}\right)=\left|H_{A V}\left(\omega_{e}\right)\right|^{2} S\left(\omega_{e}\right)
$$

The absolute vertical velocity and acceleration RAOs can be written as follows;

$$
\begin{aligned}
& \left|H_{A V}^{\prime}\left(\omega_{e}\right)\right|=\omega_{e}\left|H_{A V}\left(\omega_{e}\right)\right| \\
& \left|H_{A V}^{\prime \prime}\left(\omega_{e}\right)\right|=\omega_{e}^{2}\left|H_{A V}\left(\omega_{e}\right)\right|
\end{aligned}
$$

The relative motion $\mathrm{RAO}$ and phase formulation is also given by Lloyd [26]. For instance, the RAO of the relative vertical motion is as follows;

$\left|H_{R V}\left(\omega_{e}\right)\right|=\sqrt{\left|H_{A V}\right|^{2}-2\left|H_{A V}\right| \bar{\zeta} \cos \left(\sigma_{A V}+Q\right)+\bar{\zeta}^{2}}$

where $Q=k \bar{x} \cos \mu$. For the ships in head seas $Q=-k \bar{x}$. The phase of the relative vertical motion is given by the following equation.

$$
\sigma_{R V}=\arctan \left(\frac{\left|H_{A V}\right| \sin \sigma_{A V}+\bar{\zeta} \sin Q}{\left|H_{A V}\right| \cos \sigma_{A V}+\bar{\zeta} \cos Q}\right)
$$

The time series data for the relative vertical motion at any point of the ship can be generated as follows;

$$
\eta_{R V}(t)=\eta_{3}(t)-\bar{x} \eta_{5}(t)-\zeta(\bar{x}, t)
$$

The time series data for the absolute and relative vertical motion velocity and acceleration at any point (bow, midships or stern) can be derived by differentiating the absolute and relative vertical motion time series data (49)\&(62) once and twice respectively.

The expressions are slightly different for the hydroelasticity theory [32], as investigated by Belik [1]. For the symmetric response of ships in long-crested irregular head seas, the RAO for the vertical distortions of a ship section is expressed as follows $[1,3]$;

$|w(x)|=\left|\sum_{r=0}^{n} p_{r} w_{r}(x)\right|$

where $x$ is the distance from the aft perpendicular of the ship, $p_{r}$ represents the complex quantities called "principle coordinates" and $w_{r}(x)$ represents the "principle mode shapes" of the symmetric vibration. The above superposition algorithm needs care similar to Equation (51) and (53), since the polar form of complex quantities has amplitudes and phases.

The principle coordinates consist of "rigid body" modes $(r=0,1)$ and the distortion modes $(r=2,3, \ldots, n)$ [32]. The bodily principal coordinates for the rigid modes are the heave and pitch motions of the ship respectively;

$\left|p_{0}\right|=\left|H_{3}\left(\omega_{e}\right)\right|$

$\left|p_{1}\right|=\frac{L_{B P}}{2} \sin \left(k\left|H_{5}\left(\omega_{e}\right)\right|\right)$

where $L_{B P}$ is the ship's between perpendiculars and $k$ is the wave number. The principle mode shapes for the rigid modes $(r=0,1)$ are shown in References $[1,2,3,32]$. Since mode shapes are a function of $x / L_{B P}$, for the rigid body modes only, Equation (63) becomes the absolute vertical motion similar to Equation (53).

Similar to Equation (46), the time series data for the principle coordinates can be generated by the following algorithm [2];

$w(x, t)=\sum_{j=1}^{m} \sum_{r=0}^{n} \bar{\zeta}_{j}\left|p_{r, j}\right| w_{r}(x) \cos \left(\omega_{e j} t+\arg \left(p_{r, j}\right)+\varepsilon_{j}\right)$ 


\section{Validation}

Validation of the time series of wave elevation and all responses, including the derived ones can be performed using the spectral analysis technique which includes discrete Fourier transform (DFT), and smoothing algorithms, as explained by Belik [1] and Newland [34].

For the spectral analysis, the time step of the simulation should be selected as follows [1, 34];

$$
\Delta t=\frac{\pi}{\omega^{*}}
$$

Here $\omega^{*}$ is the "Nyquist frequency" in radians per second, which is the highest wave or encounter frequency used for the generation of the time series. The time length of the simulation with $N$ discrete data points becomes as follows [1];

$T_{N}=N \Delta t$

The number of discrete data points should be a power of two as a condition of the fast Fourier transform (FFT) algorithm. Therefore the time series data must be extended by adding $L$ additional zeros as amplitude [1, 34];

$$
N+L=2^{p}
$$

where $p$ is a positive integer. The extended time length of the discrete data points with the additional zeros becomes as follows;

$$
T_{L}=(N+L) \Delta t
$$

The DFT algorithm for the $N+L$ data points is defined as follows [1, 34];

$$
X_{k}=\frac{1}{N+L} \sum_{n}^{N+L-1} x_{n} \exp \left(-i \frac{2 \pi n k}{N+L}\right) \text { for } k=0,1, \ldots, N+L-1
$$

Here $X_{k}$ is the th complex Fourier coefficient, $x_{n}$ is the $n^{\text {th }}$ discrete data point of the time series, including the additional zeros, and $i$ is the imaginary unit of a complex number. The above algorithm (70) can also be performed using the built in MATLAB commands "nextpow2" and "fft";

$$
X_{k}=\left(1 / 2^{\wedge} \text { nextpow } 2(N)\right) * \operatorname{fft}\left(x_{n}\right)
$$

The corresponding circular frequency in radians per second for the $k^{\text {th }}$ coefficient is as follows [1, 34];

$$
\omega_{k}=\frac{2 \pi k}{T_{L}}
$$

The DFT is valid for frequency up to the Nyquist frequency. From Equation (66) and (69) following relation can be written to find the maximum value of the $k$ [34];

$$
\omega^{*}=\frac{2 \pi k_{\max }}{(N+L) \Delta t}=\frac{\pi}{\Delta t}
$$

As shown in the above equation, the maximum value of the $k$ for the validation should be as follows;

$$
k_{\max }=\frac{N+L}{2}
$$

Therefore, the DFT algorithm for the validation is defined as follows $[1,34]$;

$X_{k}=\frac{1}{N+L} \sum_{n}^{N+L-1} x_{n} \exp \left(-i \frac{2 \pi n k}{N+L}\right)$ for $k=0,1, \ldots, \frac{N+L}{2}$

The $k^{\text {th }}$ real Fourier coefficient is given as follows $[1,34]$;

$S_{k}=X_{k}^{*} X_{k}=\left|X_{k}\right|^{2}$

where $X_{k}^{*}$ is the complex conjugate of the $X_{k}$. The ordinates of the continuous spectral estimate are given as follows [1, 34];

$S^{\prime}\left(\omega_{k}\right)=\frac{N+L}{N} \frac{T_{L}}{2 \pi} S_{k}$

Here $(N+L) / N$ is the correction factor for the additional zeros. The smoothing of the spectral estimate ordinates "to increase their statistical reliability" can be performed with the following algorithm [1, 34];

$\bar{S}\left(\omega_{k}\right)=\frac{1}{2 s+1} \sum_{q=-S}^{S} S^{\prime}\left(\omega_{k+q}\right)$ for $k=0,1, \ldots, \frac{N+L}{2}$

where $2 s+1$ is the span of the smoothing process;

$$
2 s+1=\frac{N+L}{N} T_{N} \beta_{e}=T_{L} \beta_{e}
$$


Here $\beta_{e}$ is the "effective bandwidth", i.e. the frequency interval for the smoothing

$\beta_{e}=\frac{2 s+1}{T_{L}}$

The dimension of the effective bandwidth is Hertz $(\mathrm{Hz})$, since the frequency step for the spectral estimates in Equation (78) is $2 \pi / T_{L}$ in radians per second, as shown by Equation (72). Belik [1] expressed the effective bandwidth as the following;

$\beta_{e}=\frac{2 \pi}{\alpha^{2} T_{N}} \quad(0<\alpha<1)$

Here as $\alpha$ tends to zero the precision of the spectral estimate in the effective bandwidth increases. The above algorithm (78) can also be performed using the built in the MATLAB command "smooth with default "moving" method";

$\bar{S}(\omega)=\operatorname{smooth}\left(S^{\prime}(\omega), \quad 2 s+1, \quad\right.$ 'moving' $)$

In conclusion, according to Price and Bishop [28] (cited by Belik [1]) the "physically realizable one sided spectral density function" is as follows;

$\phi(\omega)=2 \bar{S}(\omega)$

For the validation, the spectral density functions derived from time series data with above process were compared to the original pre-calculated spectra which were used for the generation of the time series at 350 frequency abscissae. The time series were generated using ITTC Two-Parameter Spectrum at "sea-state 6" for the Northern Hemisphere.

The long-crested irregular wave elevation time histories generated by Equation (26) at a fixed point and the corresponding spectral validations are shown in Figure 5 and Figure 6. The maximum wave frequency, i.e. the Nyquist frequency is 1.60 radians per second. The length of the first time series is 5400 seconds and $\alpha=0.26$. The length of the second time series is 1800 seconds and $\alpha=0.45$. The length of the time series and the effective bandwidth changes the accuracy of the derived spectral density function as Newland [34] stated. For the further validation studies the length of each time series is 1800 seconds and $\alpha=0.45$. For the short-crested wave data, the spectral validation can be performed separately for each secondary wave direction component. For example, the component series for $v-\mu=0^{\circ}$ and $v-\mu=75^{\circ}$ with $\delta v=15^{\circ}$ and the corresponding spectral validations are shown in Figure 7 and Figure 8 respectively.

Heave and pitch motion time history (in long-crested seas) of a DTMB Model 5415 representing the preliminary design of the DDG-51 hull form [35] (in forward motion with the Froude number of 0.41), derived from Equation (46), shown in Figure 9 and Figure 10 was validated like the wave time history. The maximum encounter frequency, i.e. the Nyquist frequency is 2.50 radians per second. The motion time series in short-crested seas can also be validated separately for each secondary wave direction component.

The absolute vertical motion time histories at bow and stern of a frigate generated by Equation (49) and the spectral validations are shown in Figure 11 and Figure 12.

\section{Summary and Conclusions}

In this study, the simulation-based analysis method (a.k.a. the real time computer experiment method) of ship motions and wave elevation was discussed with the procedure of spectral validation. For this purpose, visually simulated time series of ship motions and wave elevation were generated for the demonstration and analysis of the pre-calculated seakeeping results. Validation of the time series of wave elevation and all responses, including the derived ones were performed using the spectral analysis technique which includes discrete Fourier transform (DFT), and smoothing algorithms. It is found that this analysis method can be adapted 


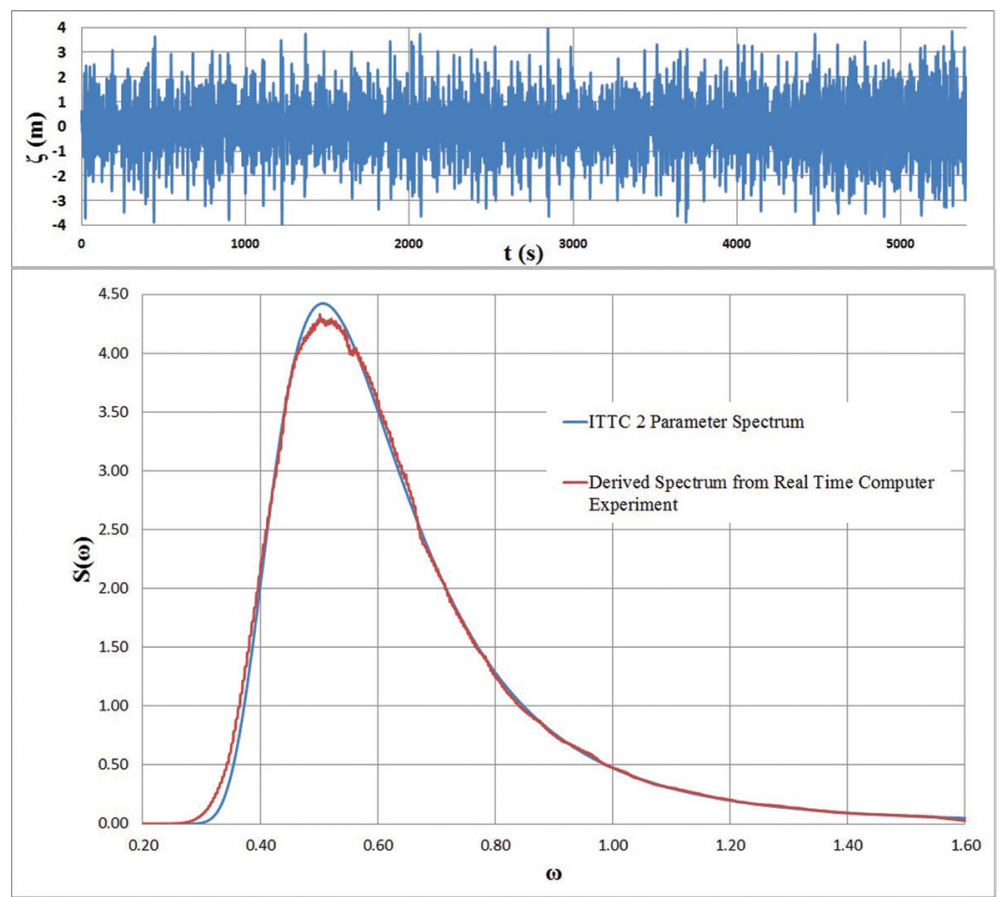

Figure 5. Long-Crested Irregular Wave Time History (5400 seconds) and Spectral Validation (RMS Amplitude $=1.25 \mathrm{~m}$, Significant Amplitude $=2.5 \mathrm{~m}$ )

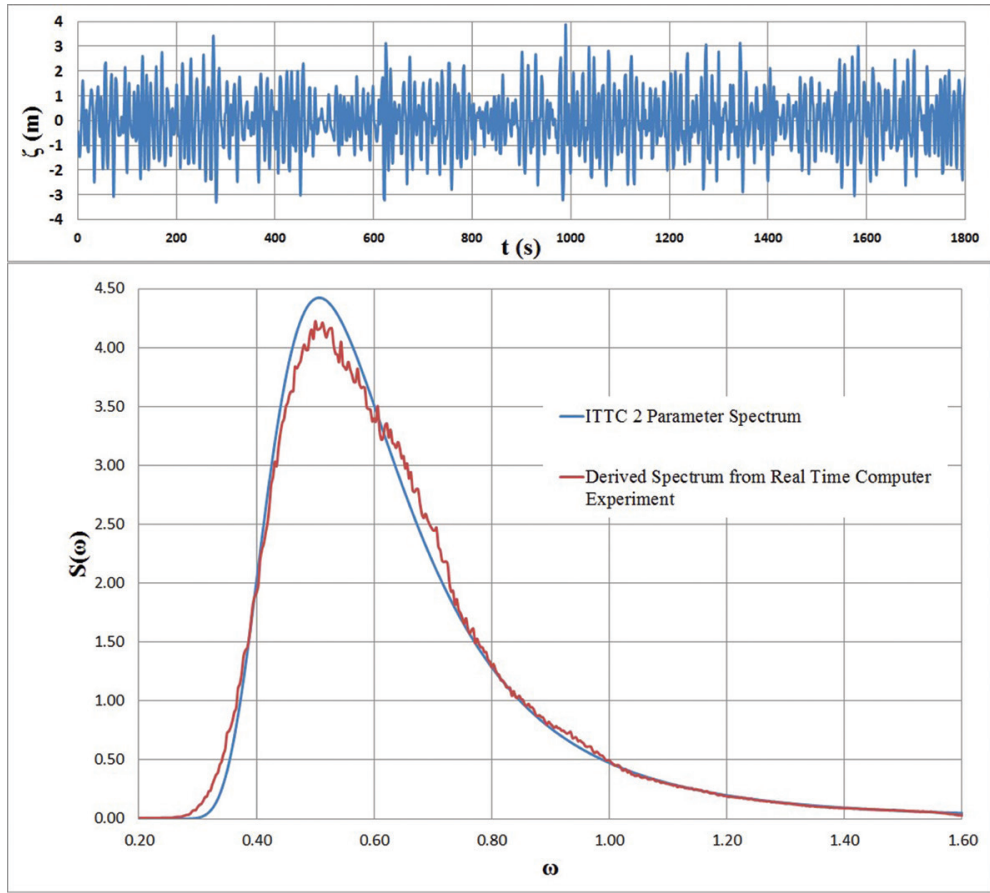

Figure 6. Long-Crested Irregular Wave Time History (1800 seconds) and Spectral Validation (RMS Amplitude $=1.25 \mathrm{~m}$, Significant Amplitude $=2.5 \mathrm{~m}$ ) 


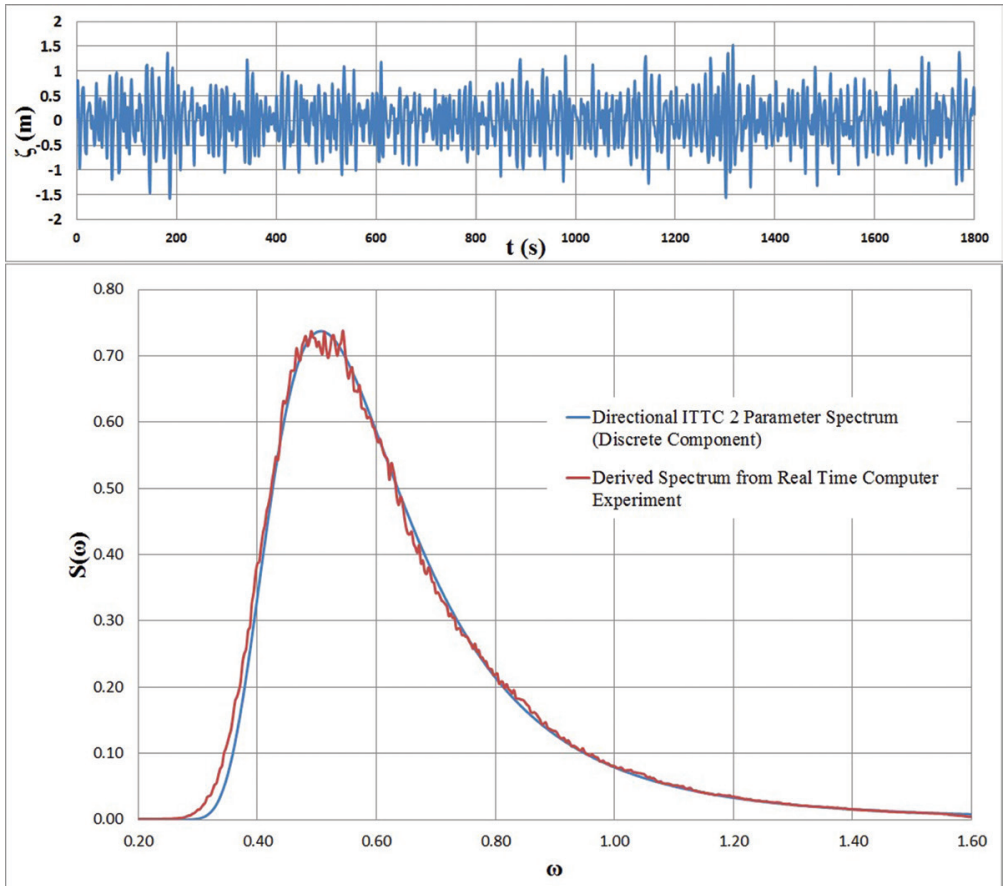

Figure 7. Short Crested Irregular Wave Time History Component (for $v-\mu=0^{\circ}$ and $\delta v=15^{\circ}$ ) and Spectral Validation

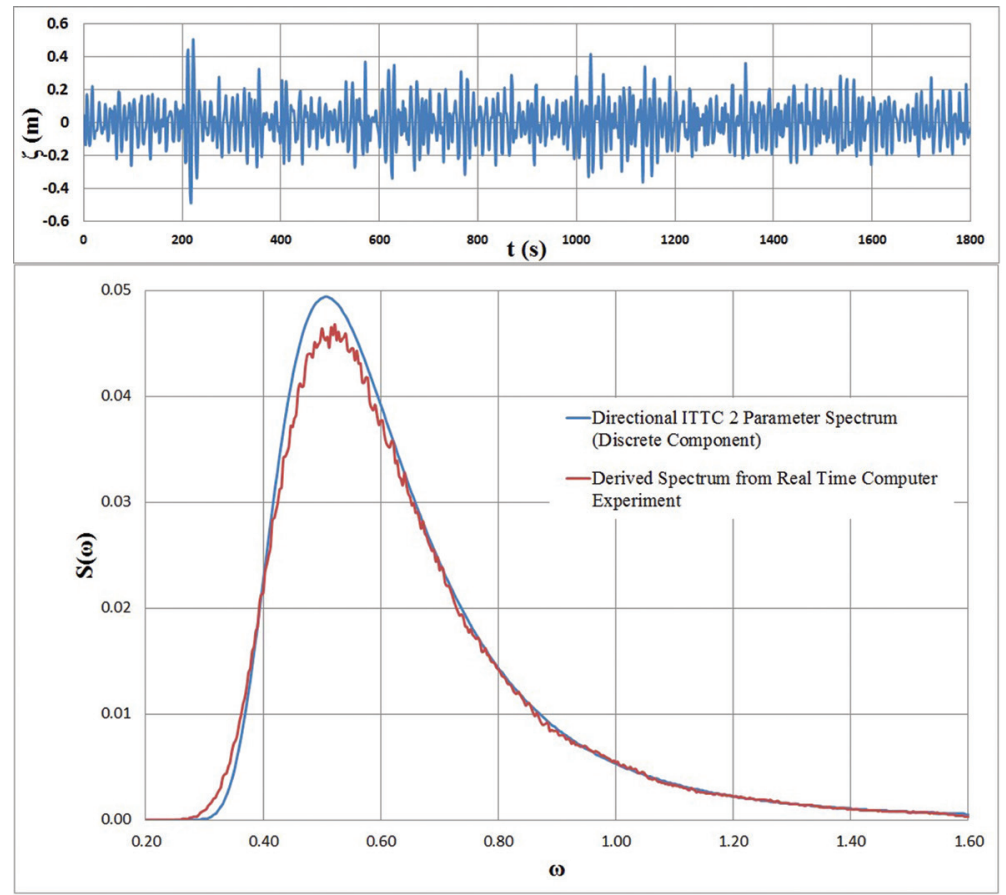

Figure 8. Short Crested Irregular Wave Time History Component (for $v-\mu=75^{\circ}$ and $\delta v=15^{\circ}$ ) and Spectral Validation 

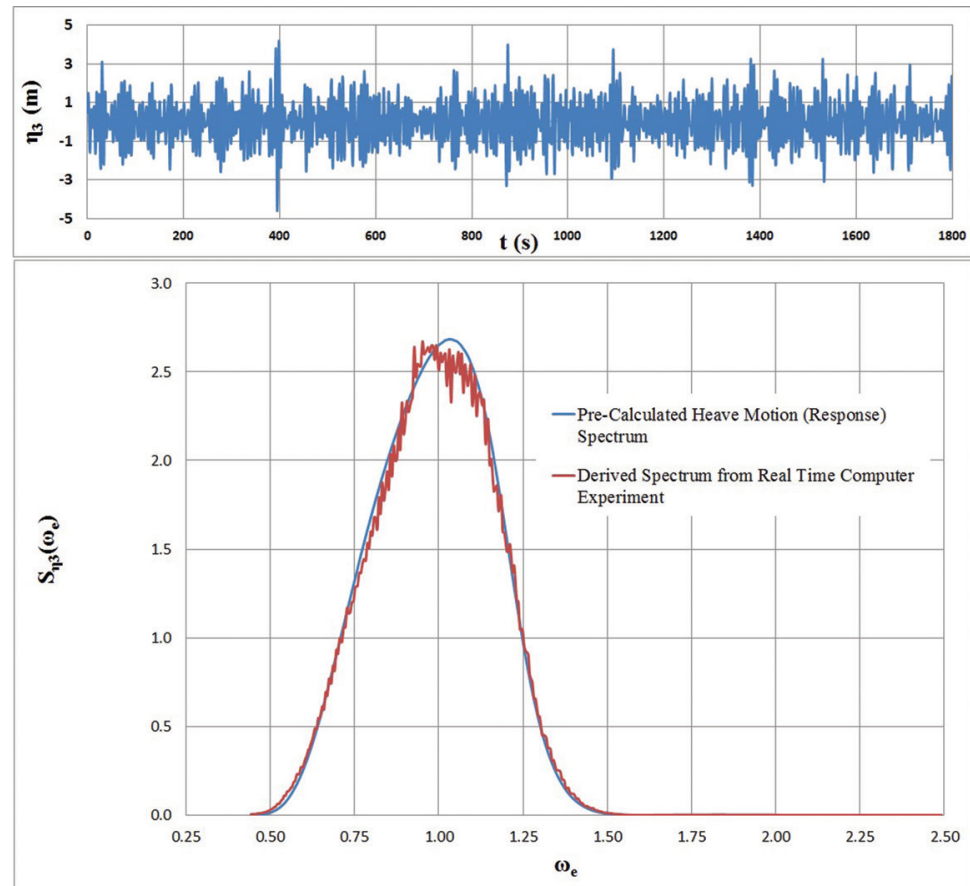

Figure 9. The Heave Motion Time History (In Long-Crested Seas) and Spectral Validation (RMS Amplitude $=1.12 \mathrm{~m}$, Significant Amplitude $=2.24 \mathrm{~m}$ )

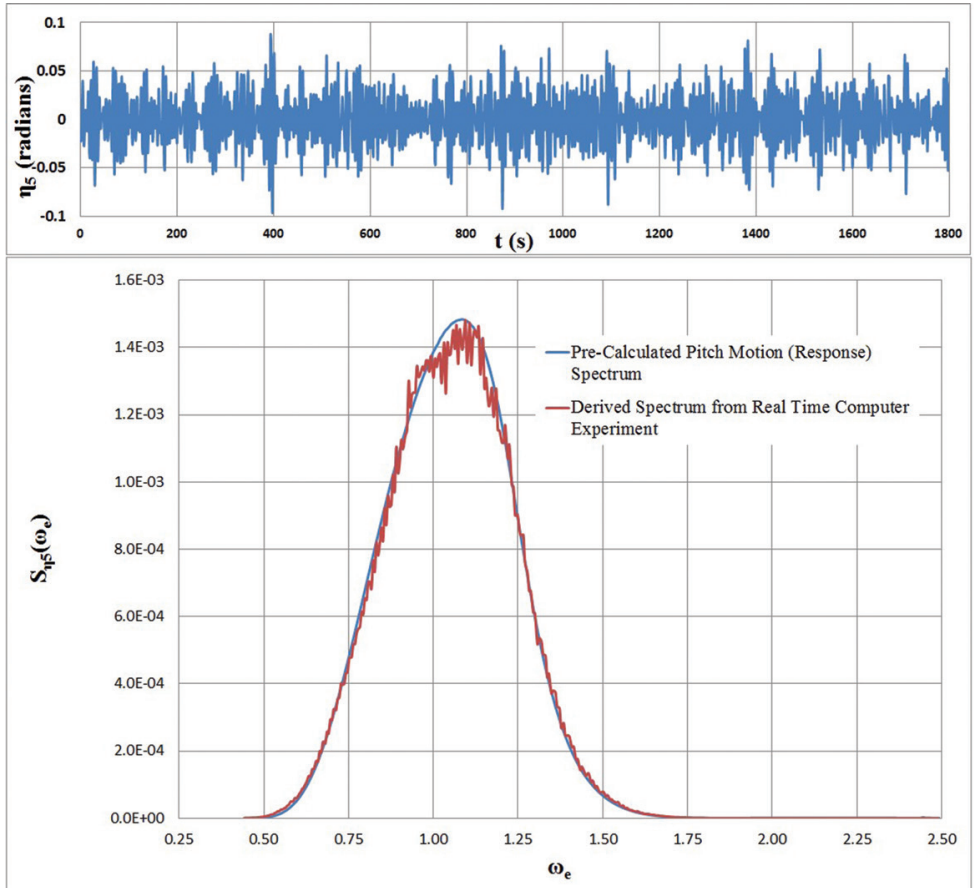

Figure 10. The Pitch Motion Time History (In Long-Crested Seas) and Spectral Validation (RMS Amplitude $=0.0266$ radians, Significant Amplitude $=0.0532$ radians) 


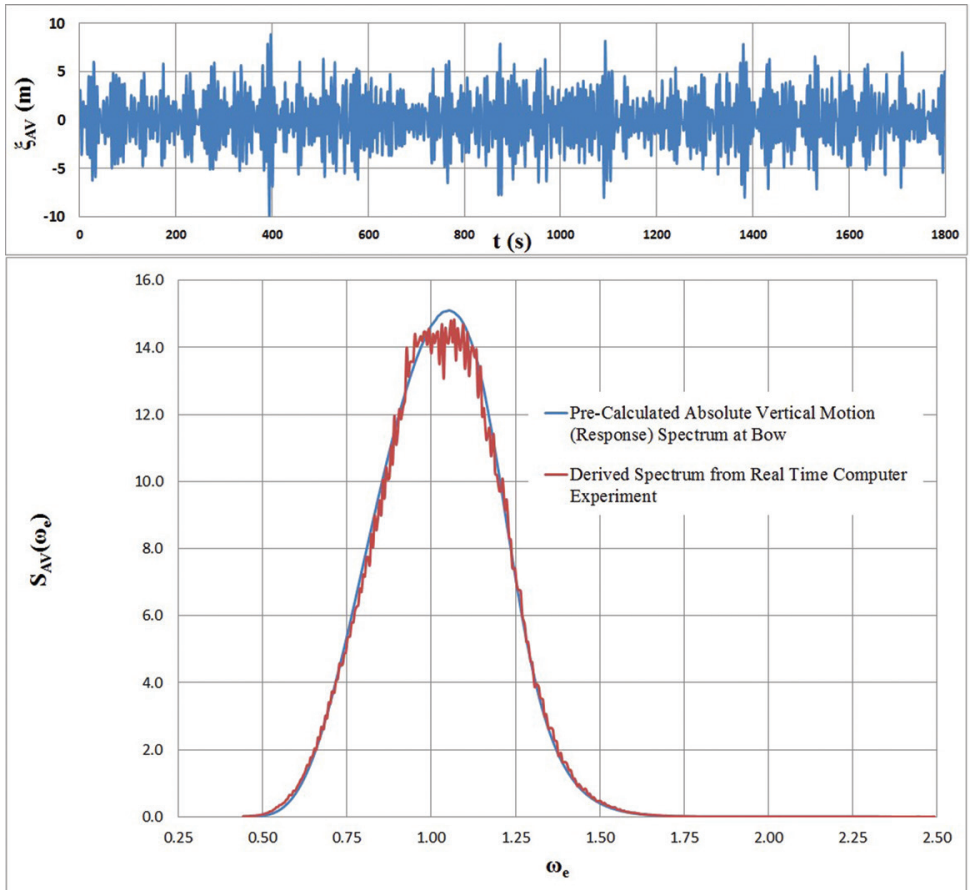

Figure 11. The Absolute Vertical Motion Time History at Bow (In Long-Crested Seas) and Spectral Validation (RMS Amplitude $=2.63 \mathrm{~m}$, Significant Amplitude $=5.26 \mathrm{~m}$ )

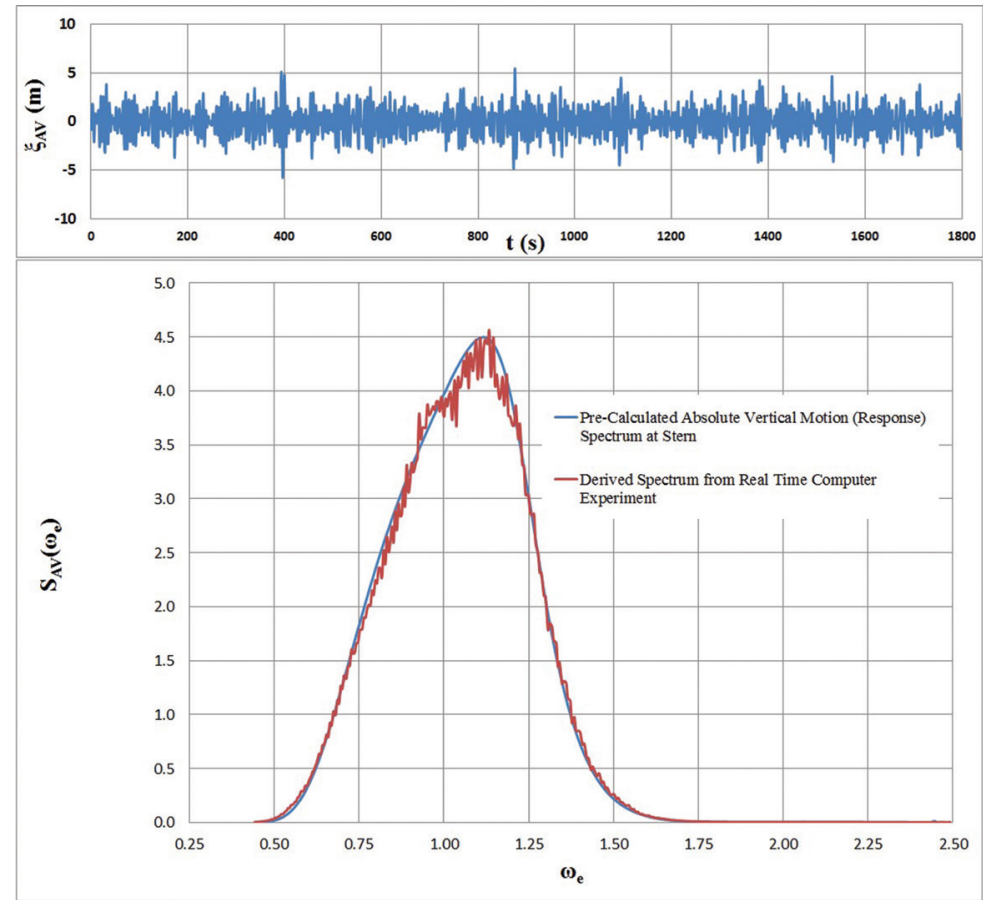

Figure 12. The Absolute Vertical Motion Time History at Stern (In Long-Crested Seas) and Spectral Validation (RMS Amplitude $=1.50 \mathrm{~m}$, Significant Amplitude $=3,00 \mathrm{~m}$ ) 
to design and validation studies for both the naval platform itself and the systems on board effectively. The analysis of the simulation results provides sufficient information about the extreme motions and accelerations. Observation of the deck wetness, slamming or emergence at any location is also feasible from the relative motion time history. Utilizing the ship hydroelasticity theory [32], the vertical distortion, shear force and bending moment distribution of ship sections can be acquired by these computer experiments. Furthermore, the results of this study may also be suitable for the ship-handling simulators or helicopter landing on ship simulations for more realistic visualization.

As indicated by Belik and Gökmen [2] the importance of the simulation-based analysis is its practical and innovative nature. The desired length of time series data for any ship response, including the derived ones can be generated without any cost and restrictions except the computer performance. Comparison of the performance of different hull forms in the same irregular sea condition is possible with this simulation technique. If supported by experimental results, a database of the responses from the different type of hull forms can also be generated. Moreover, the real time simulation-based analysis method may prevent the over-design issues and allow the refinement of the design criteria for both the naval platform itself and the systems on board.

\section{References}

[1] Belik, M.Ö. (1982). Symmetric Response of Ships in Regular and Irregular Waves, Doctoral thesis, University College London.

[2] Belik, M.Ö. and Gökmen, M. (1995). Gemilerin Așırı Deniz Şartlarında DavranışınınBilgisayarlaSimülasyonu. Deniz Kuvvetleri Komutanlığı, 2inci Teknik Sempozyumu, İstanbul, 1995.
[3] Başaran, İ. (2005). Responses of Ships in Extreme Sea Conditions, Thesis (M.Sc.), İstanbul Technical University, Institute of Science and Technology, İstanbul. Retrieved: 12 March 2016, from: http://hdl.handle. net/11527/11939.

[4] Yeo, D.J., Cha, M. and Mun, D. (2012). Simulating ship and buoy motions arising from ocean waves in a ship handling simulator. Simulation: Transactions of the Society for Modeling and Simulation International, 2012:88(12):14071419. Retrieved: 07 June 2013, from: http://sim.sagepub.com/ content/88/12/1407.full.pdf+html.

[5] Menteş, A., Yetkin, M., Türkoğlu N., Yalçın, İ. , Akyıldız, H. and Helvacıoğlu, İ.H. (2013). Açık Deniz Petrol Platformu Modellemesinde Yapay Sinir Ağları Yaklaşımı. Journal of ETA Maritime Science, 2013:1(2):1-8.

[6] He, B., Wang, W., Zhang, Y. and Liu, L. (2016) A Simulation Model of a Helicopter Landing on a Ship. International Journal of Simulation Systems, Science \& Technology, 2016:17(25):5.1-5.7.

[7] OGRE3D (2013). Open Source 3D Graphics Engine. Retrieved: 04 February 2013, from: http://www. ogre3d.org/.

[8] Adanır, İ.R., Schoenwaelder, B. and Schumann, L. (2002). Ship Motion Simulation., Project. The University of Michigan Virtual Reality Laboratory (VRL) at the College of Engineering, Ann Arbor. Retrieved: 05 May 2012, from: http://www-vrl.umich.edu/ sel_prj/wave_ship/.

[9] Perez, T. (2005). Ship Motion Control, Course Keeping and Roll Stabilisation Using Rudder and Fins. London: Springer-Verlag.

[10] St. Denis, M. and Pierson, W.J. (1953). On the Motions of Ships in Confused 
Seas. Transactions, Society of Naval Architects and Marine Engineers, 1953:61:280-357.

[11] Beck, R.F., Cummins, W.E., Dalzell, J.F., Mandel, P. and Webster, W.C. (1989). Motion in Waves. In E.V. Lewis, (Ed.), Principles of Naval Architecture (2nd revision, Vol. 3) (pp. 1-190). Jersey City, NJ: The Society of Naval Architects and Marine Engineers.

[12] Salvesen, N., Tuck, E.O. and Faltinsen, O. (1970). Ship Motions and Sea Loads. Transactions, Society of Naval Architects and Marine Engineers, 1970:78:250-279.

[13] González, X.V. (2008). Hydrax. Version 0.5.1. Ogre3D add-on library. Retrieved: 04 February 2013, from: http://www.ogre3d.org/tikiwiki / Hydrax.

[14] Johanson, C. (2004). Real-time water rendering, Introducing the projected grid concept, Thesis (M.Sc.), Department of Computer Science, Lund University, Lund Sweden. Retrieved: 29 May 2013, from: http:// fileadmin.cs.lth.se/graphics/theses/ projects/projgrid/ projgrid-lq.pdf.

[15] WMO Manual on Codes (Publication No.306) (2015). International Codes, Volume I.1, Annex II to the WMO Technical Regulations, Part A - Alphanumeric Codes, 2011 ed., Updated in 2015. Retrieved: 02 June 2016, from: http://www.wmo.int/ pages / prog/www / WMOCodes / WM0306_vI1/VolumeI.1.html.

[16] STANAG 4154 (2000). Common Procedures for Seakeeping in the Ship Design Process (3rd Ed.), NATO Military Agency for Standardisation.

[17] Sverdrup, H. U. and Munk, W. H. (1947). Wind, Sea and Swell: Theory of Relations for Forecasting (H.O.Pub. No. 601). U.S.Navy Department Hydrographic Office. Retrieved: 13 June 2016, from: http://archive.org.
[18] Longuet-Higgins, M.S. (1952). On the Statistical Distribution of the Heights of Sea Waves. Journal of Marine Research, 1952:11(3):245-266.

[19] 12th International Towing Tank Conference (1969). Technical Decisions and Recommendations. Rome, Italy.

[20] Pierson, W.J. and Moskowitz, L. (1964). A Proposed Spectral Form for Fully Developed Wind Seas Based on the Similarity Theory of S. A. Kitaigorodski. Journal of Geophysical Research, 1964:69(24):5181-5190.

[21] Bretschneider, C.L. (Ed.). (1959). Wave Variability and Wave Spectra for Wind Generated Gravity Waves (Technical Memorandum No.118). Beach Erosion Board, US Army Corps of Engineers.

[22] Michel, W.H. (1999). Sea Spectra Revisited. Marine Technology, 1999:36(4):211-227.

[23] 15th International Towing Tank Conference (1978). Recommendations of the Executive Committee and the Technical Committee and Panels. Hague, Netherlands.

[24] Hasselmann, K., Barnett, T.P., Bouws, E., Carlson, H., Cartwright, D.E., Enke, K., Ewing, J.A., Gienapp, H., Hasselmann, D.E., Kruseman, P., Meerburg, A., Müller, P., Olbers, D.J., Richter, K., Sell, W., Walden, H. (1973). Measurements of Wind-Wave Growth and Swell Decay During the Joint North Sea Wave Project (JONSWAP). Ergänzungsheft zur Deutschen Hydrographischen Zeitschrift, Reihe $\mathrm{A}(80)$, Nr. 12. Retrieved: 05 June 2016, from: TU Delft Institutional Repository, http://repository.tudelft. $\mathrm{nl}$.

[25] 17th International Towing Tank Conference (1984). Report of Seakeeping Committee, Recommendations Concerning the Work of the Information Group and 
the Technical Committees Adopted by the 17th ITTC. Göteborg, Sweden.

[26] Lloyd, A.R.J.M. (1989). Seakeeping: Ship Behaviour In Rough Weather. Chichester, West Sussex: Ellis Horwood Limited.

[27] 18th International Towing Tank Conference (1987). Report of Seakeeping Committee. Kobe, Japan.

[28] Price, W.G. and Bishop, R.E.D. (1974). Probabilistic Theory of Ship Dynamics. London: Chapman and Hall.

[29] Beck, R.F. and Reed, A.M. (2001). Modern Computational Methods for Ships in a Seaway. Updated version of a paper prepared as an invited lecture for the Twenty-third Symposium on Naval Hydrodynamic.

[30] Newman, J.N. (1978). Theory of Ship Motions. Advances in Applied Mechanics, 1978:18:221-283.

[31] 9th International Towing Tank Conference (1960). Seagoing Qualities of Ships. Paris, France.

[32] Bishop, R.E.D. and Price, W.G. (1979). Hydroelasticity of Ships. Cambridge: Cambridge University Press.

[33] Flexible Learning Approach to Physics (1994) Physics Module P5.1, Simple Harmonic Motion, The Open University. Retrieved: 22 May 2016, from: http://www.physics.ox.ac.uk/ teach/FLAP/FLAP/P5.1.pdf.

[34] Newland, D.E. (1993). An Introduction to Random Vibrations, Spectral and Wavelet Analysis (3rd ed.). New York: John Wiley \& Sons.

[35] Ratcliffe, T.J., Mutnick, I. and Rice, J. (2001). Stern Wave Topography and Longitudinal Wave Cuts Obtained on Model 5415, With and Without Propulsion (NSWCCD50-TR-2000/028). West Bethesda, Maryland: David Taylor Model Basin Naval Surface Warfare Center, Carderock Division. 